\title{
Improvement of pressurised aerosol deposition with Nebuhaler spacer device
}

\author{
STEPHEN P NEWMAN, ANN B MILLAR, TIMOTHY R LENNARD-JONES, \\ FOLKE MORÉN, STEWART W CLARKE
}

From the Department of Thoracic Medicine, Royal Free Hospital, London; and AB Draco, Lund, Sweden

ABSTRACT The effect on aerosol deposition from a pressurised metered dose inhaler of a $750 \mathrm{~cm}^{3}$ spacer device with a one way inhalation valve (Nebuhaler, Astra Pharmaceuticals) was assessed by means of an in vivo radiotracer technique. Nine patients with obstructive lung disease took part in the study. The pattern of deposition associated with use of a metered dose inhaler alone was compared with that achieved with the spacer used both for inhalation of single puffs of aerosol and for inhalation of four puffs actuated in rapid succession and then inhaled simultaneously. On each occasion there was a delay of $1 \mathrm{~s}$ between aerosol release and inhalation, simulating poor inhaler technique. With the metered dose inhaler alone, a mean (SEM) 8.7 (1.8)\% of the dose reached the lungs and $80.9(1.9) \%$ was deposited in the oropharynx. With single puffs from the spacer $20.9(1.6) \%$ of the dose $(\mathrm{p}<0.01)$ reached the lungs, only $16.5(2.3) \%(\mathrm{p}<$ $0.01)$ was deposited in the oropharynx, and $55.8(3 \cdot 1) \%$ was retained within the spacer itself. With four puffs from the spacer $15.2(1.5) \%$ reached the lungs ( $\mathrm{p}=0.02$ compared with the metered dose inhaler alone, $\mathrm{p}<0.01$ compared with single puffs from the spacer), $11.4(1.2) \%$ was deposited in the oropharynx, and $67.5(1.8) \%$ in the device itself. It is concluded that the spacer device gives lung deposition of metered dose aerosols comparable to or greater than a correctly used inhaler and oropharyngeal deposition is greatly reduced. The spacer should be used preferably for the inhalation of single puffs of aerosol but may also be used for the inhalation of up to four puffs actuated in rapid succession and then inhaled simultaneously.

Metered dose inhalers have several advantages for respiratory treatment as they contain several hundred doses and are compact, unobtrusive, and apparently easy to use. The spray from a metered dose inhaler consists, however, of rapidly moving, large propellant droplets, most of which impact in the oropharynx, only about $10 \%$ penetrating into the bronchial tree. ${ }^{2}$ This small proportion may be further reduced by poor inhaler technique. Many patients misuse their inhalers, ${ }^{3}$ and failure to synchronise firing of the aerosol with inhalation is probably the most widespread problem. ${ }^{45}$

Various types of spacer attachments to the inhaler mouthpiece may improve and facilitate drug delivery to the lungs. Simple tube spacers ${ }^{67}$ enable the

Address for reprint requests: Dr SP Newman, Department of Thoracic Medicine, Royal Free Hospital, London NW3 2QG.

Accepted 18 July 1984 propellant droplets in the spray to slow down and evaporate, so that oropharyngeal deposition is reduced and lung deposition is increased. ${ }^{8}$ Holding chambers or reservoir attachments to metered dose inhalers, ${ }^{9-12}$ many of which have a one way inhalation valve in the mouthpiece, may also improve the deposition of pressurised aerosols. The aerosol may be released into the device and inhaled after a brief pause so that synchronisation between aerosol release and inhalation is unimportant. In this study we assessed the effects of a $750 \mathrm{~cm}^{3}$ spacer with a one way inhalation valve (Nebuhaler, Astra Pharmaceuticals), the shape of which is similar to that of the aerosol spray cloud (fig 1), on the deposition of pressurised aerosol using an in vivo radioaerosol tracer technique. ${ }^{2}$ We used the spacer both for the inhalation of single puffs of radioaerosol and for the inhalation of multiple (four) puffs actuated in rapid succession immediately before inhalation. The second method would simplify the use of pressurised 

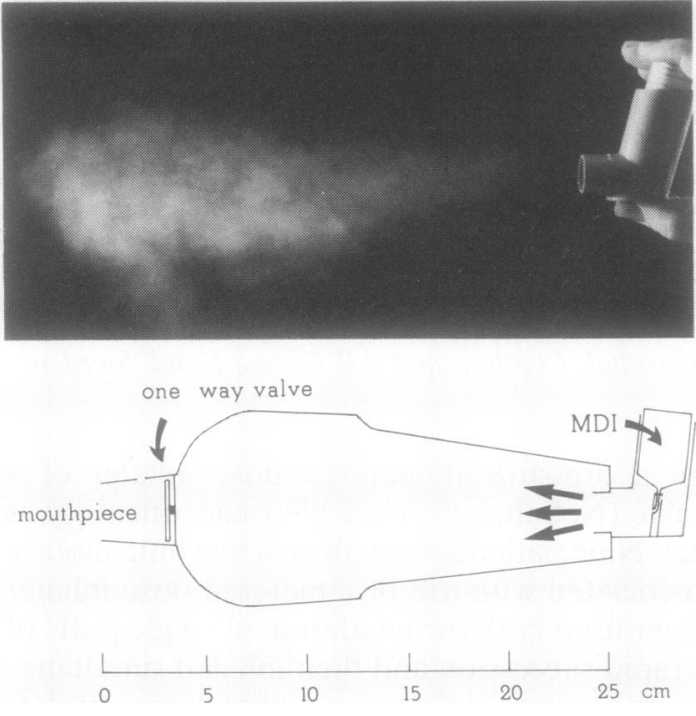

Fig 1 The metered dose aerosol spray (top) and Nebuhaler spacer device (bottom) which has a shape similar to that of the spray cloud. $M D I=$ metered dose inhaler.

aerosols, especially for patients taking large doses of bronchodilators.

\section{Methods}

\section{PATIENTS}

Measurements of radioaerosol deposition were carried out in nine patients with airflow limitation: five had asthma and four had chronic obstructive lung disease with a mean forced expiratory volume in one second $\left(\mathrm{FEV}_{1}\right) \mathbf{8 0 . 3 \%}$ of predicted and a range of 29-132\% predicted. All patients were current users of pressurised bronchodilator aerosols, and five were also using corticosteroid aerosols. The patients continued to take their usual treatment throughout the study. Table 1 gives details of the patients.
Before inhaling radioaerosol $\mathrm{FEV}_{1}$, forced vital capacity (FVC), and maximum mid-expiratory flow rate (MMEF) were measured using a Vitalograph spirometer, and peak expiratory flow rate (PEFR) was measured with a Wright peak flow meter.

\section{RADIOAEROSOL TECHNIQUE}

Pressurised aerosol deposition was measured by incorporating Teflon particles, labelled with $\vec{\omega}$ technetium-99m, into pressurised canisters and then recording their presence in the body after inhalation $x$ with external radiation detectors. ${ }^{2813}$ A spinning $\underset{\oplus}{\omega}$ disc generator ${ }^{14}$ was used to manufacture the Teflon $\vec{N}$ particles, which had a mass median aerodynamic $c 0$ diameter of $3.2 \mu \mathrm{m}$, which is similar to that of bron- $\underset{\mathcal{G}}{\mathcal{G}}$ chodilator or corticosteroid drug crystals. ${ }^{15}$ The 을 geometric standard deviation of the particles was $1 \cdot 2$. These particles were placed inside small canisters together with $2 \mathrm{~cm}^{3}$ of chlorofluorocarbon propellants 11,12 , and 114 (in the ratio 1 to 2 to 1 ) and sorbitan trioleate surfactant $\left(14 \mathrm{mg} / \mathrm{cm}^{3}\right)$, and the canisters were sealed with a metering valve. The propellant vapour pressure was $374 \mathrm{kPa}$ $(280 \mathrm{~cm} \mathrm{Hg})$ at $20^{\circ} \mathrm{C}$, and each metered dose comprised $25 \mu \mathrm{l}$ of propellant containing the labelled particles.

Aerosol inhalation was performed with the metered dose inhaler connected in series with a Fleisch heated pneumotachygraph, the signal from $\stackrel{\unrhd}{\circledR}$ which was passed to an electronic flow integrator $\overrightarrow{\vec{A}}$ (Gould-Godart 17212) and thence to an electromedical multi-channel amplifier system ( $\mathrm{SE} \supset$ Laboratories). Inhaled flow rate and volume were displayed on an ultraviolet recorder (SE Laboratories). An observer noted the instant of aerosol release by pressing an event marker. After $\stackrel{\sim}{\times}$ each inhalation manoeuvre the patient exhaled $\bar{\sigma}$ through a low resistance bidirectional bacterial filter 3 . (Inspiron 002290) and then mouth washed and 0 gargled with water to clean the mouth and throat. After the complete inhalation procedure the patient ?

Table 1 Details of patients studied

\begin{tabular}{|c|c|c|c|c|c|c|}
\hline Case No & $\begin{array}{l}\text { Age } \\
\text { (years) }\end{array}$ & Sex & $\begin{array}{l}\text { Height } \\
\text { (m) }\end{array}$ & $\begin{array}{l}\text { Weight } \\
\text { (kg) }\end{array}$ & Diagnosis & $\begin{array}{l}F E V_{1}^{*} \\
\text { (\% predicted) }\end{array}$ \\
\hline $\begin{array}{l}1 \\
2 \\
3 \\
4 \\
5 \\
6 \\
7 \\
8 \\
9\end{array}$ & $\begin{array}{l}37 \\
54 \\
60 \\
66 \\
77 \\
46 \\
19 \\
72 \\
43\end{array}$ & $\begin{array}{l}\mathbf{F} \\
\mathbf{M} \\
\mathbf{F} \\
\mathbf{M} \\
\mathbf{F} \\
\mathbf{M} \\
\mathbf{F} \\
\mathbf{M} \\
\mathbf{F}\end{array}$ & $\begin{array}{l}1.64 \\
1.82 \\
1.58 \\
1.57 \\
1.49 \\
1.75 \\
1.72 \\
1.73 \\
1.74\end{array}$ & $\begin{array}{l}52 \\
94 \\
50 \\
71 \\
46 \\
75 \\
59 \\
65 \\
76\end{array}$ & $\begin{array}{l}\text { Asthma } \\
\text { Bronchitis } \\
\text { Bronchitis } \\
\text { Asthma } \\
\text { Bronchitis } \\
\text { Asthma } \\
\text { Asthma } \\
\text { Bronchitis } \\
\text { Asthma }\end{array}$ & $\begin{array}{r}127 \cdot 7 \\
29 \cdot 1 \\
61 \cdot 3 \\
124 \cdot 2 \\
53 \cdot 0 \\
60 \cdot 0 \\
132 \cdot 2 \\
44 \cdot 8 \\
90 \cdot 0\end{array}$ \\
\hline $\begin{array}{l}\text { Mean } \\
\text { SD }\end{array}$ & $\begin{array}{l}53 \\
18\end{array}$ & & $\begin{array}{l}1 \cdot 67 \\
0 \cdot 10\end{array}$ & $\begin{array}{l}65 \\
15\end{array}$ & & $\begin{array}{l}80 \cdot 3 \\
13 \cdot 1\end{array}$ \\
\hline
\end{tabular}

*Forced expiratory volume in one second. 
swallowed more water before eating a small piece of sticky toffee bar, which cleared particles from the oesophagus.

Radioaerosol retained in the body was measured by profile scanning of the head and trunk using a whole body counter (Nuclear Enterprises), with slit collimators, having scintillation detectors above and below a moving couch. ${ }^{28}$ The profile scan consisted of three characteristic peaks corresponding to radioaerosol located in the oropharynx, lungs, and stomach. The geometric mean counts of the upper and lower detectors were calculated at intervals of $5 \mathrm{~s}$ during the scan to correct for the depth of the radioactive source within the body, ${ }^{16}$ and further geometric corrections were made to allow for the different counting efficiences of the various body regions. ${ }^{16}$ Oropharyngeal, lung, and stomach components of the scan were analysed in the following manner. On a separate day a profile distribution of radioaerosol in the stomach was obtained by actuating several metered doses of radioaerosol into the mouth immediately after an inhalation to total lung capacity. The profile scan of this distribution was normalised and subtracted from the profile scans obtained after radioaerosol inhalation. Of the remaining radioactivity, that below the level of the sternal notch was taken to be in the lungs and that above in the oropharynx. Lung deposition and oropharyngeal deposition were expressed as percentages of the administered dose, oropharyngeal deposition being calculated as the sum of radioaerosol recorded in mouthwashings and that detected over the oropharynx and stomach during the profile scan.

Two small radiation detectors, placed anteriorly and posteriorly over the chest and collimated in such a way that their fields of view covered the lungs while largely excluding oropharynx and stomach, were used to measure radioactivity present in the lungs immediately after inhalation and then 24 hours later. The 24 hour whole lung retention of radioaerosol, corrected for background, radioactive decay, and the contribution of stomach radioactivity to the chest count, was assumed to represent alveolar deposition. ${ }^{17}$ Radioaerosol clearing during the first 24 hours was assumed to constitute tracheobronchial (conducting airway) deposition.

The amounts of radioaerosol in mouthwashings, aerosol actuator, and expired air filter were assessed by comparing the counts obtained from these items with those from several metered doses of radioaerosol released into a beaker of chloroform. ${ }^{18}$ The amount of aerosol located in the spacer itself was assessed in the following manner: several metered doses were released into a second Nebuhaler, which was immediately counted by a pair of scintillation detectors; the Nebuhaler from which the patient had inhaled was then counted under conditions of identical counting geometry and the counts were compared.

The pressurised radioaerosol technique has been approved both by the Isotope Advisory Panel of the Department of Health and Social Security and by the ethical practices committee of this hospital. All patients gave informed consent in writing before taking part in the studies.

\section{STUDY DESIGN}

Each patient performed three radioaerosol inhalation studies on three separate occasions at least 48 hours apart in a randomised order as follows.

Metered dose inhaler alone The patient exhaled to residual volume and the radioaerosol was released from a conventional actuator about $1 \mathrm{~s}$ before start of inhalation. The patient then inhaled slowly and steadily (roughly $30 \mathrm{l} / \mathrm{min}$ ) to total lung capacity with the lips closed round the mouthpiece and held his or her breath for $10 \mathrm{~s}$ before exhaling. Four single puffs of radioaerosol were administered in this manner.

Nebuhaler with single puffs The patient exhaled to residual volume and the aerosol was fired into the spacer roughly $1 \mathrm{~s}$ before the start of inhalation. The patient then inhaled slowly and steadily (roughly $30 \mathrm{l} / \mathrm{min}$ ) to total lung capacity and held his or her breath for $10 \mathrm{~s}$ before exhaling. A second slow deep inhalation was then taken from the spacer (without firing the aerosol) followed by $10 \mathrm{~s}$ of breath holding and exhalation. A total of four single puffs of radioaerosol were administered in this manner.

Nebuhaler with multiple puffs The patient exhaled to residual volume and then four puffs of radioaerosol, each separated by $1 \mathrm{~s}$, were fired into the spacer. Roughly $1 \mathrm{~s}$ after the final puff the patient began to inhale at about $30 \mathrm{l} / \mathrm{min}$ to total lung capacity and then held his or her breath for $10 \mathrm{~s}$ before exhaling. A second slow deep inhalation was then taken from the spacer (without firing the aerosol) followed by $10 \mathrm{~s}$ of breath holding and exhalation.

\section{STATISTICAL ANALYSES}

The data were assumed to be not normally distributed and were analysed by the Wilcoxon rank sum test for paired data and the Friedman two way analysis of variance by ranks. ${ }^{19} \mathrm{~A} p$ value of 0.05 was taken to indicate significance.

\section{Results}

Table 2 shows the radioaerosol deposition patterns for studies with and without the spacer. Figure 2 
Table 2 Effect of Nebuhaler spacer device on deposition of pressurised aerosols at various sites, expressed as mean (SEM) percentages of the administered dose

\begin{tabular}{llllllc}
\hline & Nebuhaler & Actuator & Exhaled Air & Oropharynx & Whole lung & $\begin{array}{c}\text { Tracheobronchial Alveolar } \\
\text { zone }\end{array}$ \\
\hline Mene
\end{tabular}

P values compared with metered dose inhaler alone: ${ }^{*}<0.05 ;^{* *} \leqslant 0.02 ;{ }^{* * *} \leqslant 0.01$.

shows whole lung deposition for the individual patients. With the metered dose inhaler alone a mean of $8.7 \%$ of the dose reached the lungs and oropharyngeal deposition averaged $80.9 \%$, the remainder being deposited on the actuator or exhaled.

When single puffs were given from the spacer, a little over half the dose (mean $55.8 \%$ ) was retained within the spacer itself. Gamma camera pictures (fig 3) showed that this aerosol was deposited either on the end wall where the spray had impacted or on the base of the device where some droplets had settled out before inhalation. Those particles reaching the patient were distributed very differently from those released from the metered dose inhaler alone (table 2). Oropharyngeal deposition was significantly $(p<0 \cdot 01)$ reduced by a factor of about five while whole lung $(p<0.01)$, tracheobronchial $(p<0.01)$, and alveolar $(p<0.05)$ depositions were more than doubled. The improved deposition pattern with the spacer was observed both for mild asthmatic subjects with FEV, greater than $100 \%$ predicted and for patients with chronic bronchitis with more severe airway obstruction $\left(\mathrm{FEV}_{1}\right.$ less than $50 \%$ predicted).

The deposition pattern when multiple puffs from

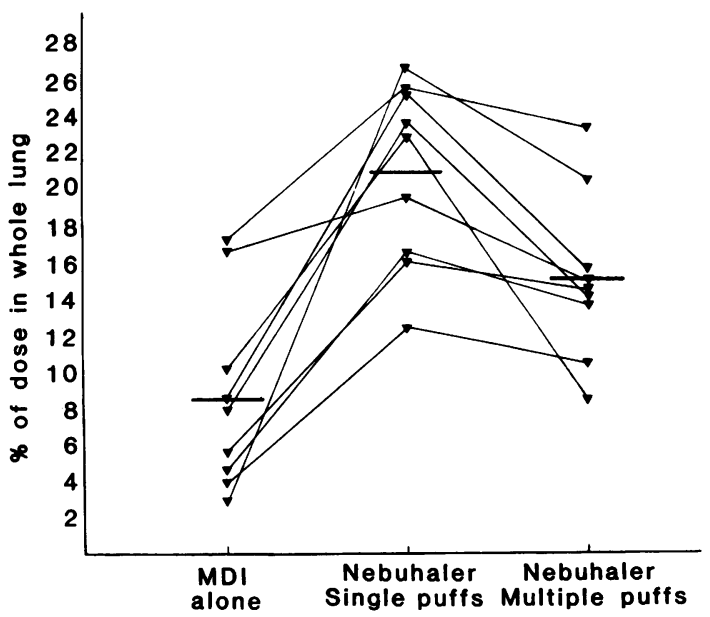

Fig 2 Effect of Nebuhaler spacer device on whole lung deposition of pressurised aerosol in nine patients with obstructive airways disease. $M D I=$ metered dose inhaler. the spacer were inhaled simultaneously broadly resembled that after inhalation of single puffs (table $\overrightarrow{\times}$ 2 ). When deposition with the spacer was compared with that achieved using the metered dose inhaler alone significant increases were seen in whole lung $\vec{N}$ $(\mathrm{p}=0.02)$, tracheobronchial $(\mathrm{p}=0.02)$, and alveo- $\mathscr{E}$ lar $(\mathrm{p}<0.05)$ depositions, and oropharyngeal deposition was greatly reduced $(p<0 \cdot 01)$. Compared with single puffs from the spacer, a greater proportion of the dose was retained within the $\mathbb{D}$ device itself $(p<0.01)$ and significant reductions occurred in oropharyngeal $(p<0.01)$, whole lung ( $p$ 증 $<0.01)$, and tracheobronchial $(\mathrm{p}<0.01)$ depositions; alveolar deposition was not significantly $\vec{\bullet}$ changed.

Compared with the metered dose inhaler alone there was a significant fall in deposition on the aerosol actuator with the spacer, used with either single $(\mathrm{p}<0.05)$ or multiple $(\mathrm{p}=0.01)$ puffs. With the metered dose inhaler alone $46.2(6.5) \%$ of the dose was recovered in mouthwashings, but with the spacer there was a dramatic reduction $(0.4(0.1) \%$ with single puffs and $0.5(0.2) \%$ with multiple puffs, $p<0.01$ ). Less than $1 \%$ of the dose was exhaled, and this did not vary significantly among the inhalation techniques.

Table 3 give details of the radioaerosol inhalation manoeuvres. Among the three studies there were no significant differences in delay between firing the last dose and the start of subsequent inhalation, in the average inhaled flow rate, or in the breath holding pause, although inhaled volume was significantly $(p<0.05)$ increased for the inhalation of multiple puffs via the spacer. The breathing pattern during the first inhalation taken from the spacer immediately after aerosol release was similar to that during $N^{N}$ the second inhalation taken shortly afterwards with- N out firing the aerosol.

Indices of lung function (FEV $, \mathrm{FVC}, \mathrm{MMEF}$, and ${ }^{\mathrm{C}}$ PEFR) varied little between the three study days.

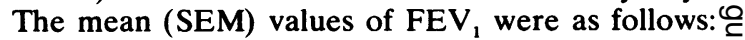
metered dose inhaler alone $2.19(0.40) \mathrm{l}$; spacer $\stackrel{\Phi}{\mathscr{Q}}$ (single puffs) $2.09(0.40) \mathrm{l}$; spacer (multiple puffs) $2.24(0.43) 1$. The mean values of MMEF were: metered dose inhaler alone $1.46(0.51) \mathrm{V} / \mathrm{s}$; spacer $\stackrel{\mathbb{D}}{ }$ (single puffs) $1.51(0.50) \mathrm{l} / \mathrm{s}$; spacer (multiple puffs) $1.69(0.50) \mathrm{l} / \mathrm{s}$. 


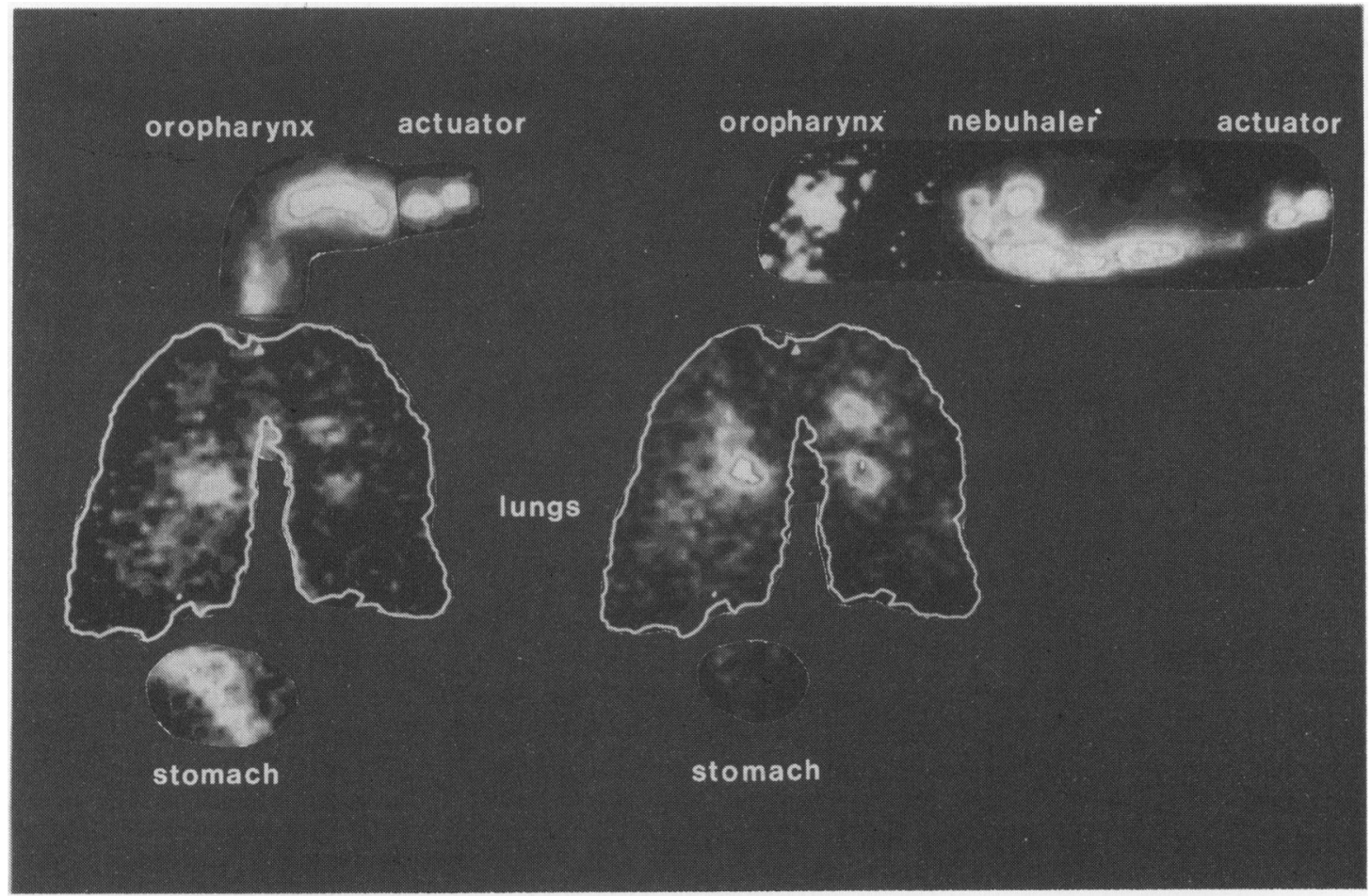

Fig 3 Gamma camera views showing typical deposition patterns for the metered dose inhaler alone (left) and for metered dose inhaler with Nebuhaler spacer attachment (right) used for inhalation of single puffs of aerosol. The patient, aged 54 years, had chronic bronchitis with a forced expiratory volume in one second (FEV) $29 \%$ predicted. The outlines of the lungs have been delineated from ventilation scans using ${ }^{81} \mathrm{Kr}^{\mathrm{m}}$ gas. Both scans are posteroanterior views.

\section{Discussion}

Less than $10 \%$ of the dose discharged from the metered dose inhaler reached the lungs because of the time delay imposed between aerosol actuation and inhalation, which was intended to simulate poor inhaler technique. With good coordination and the same inhaled flow rate and breath holding pause about $15 \%$ of the dose would have been expected to reach the lungs. ${ }^{13}$ Using the Nebuhaler spacer device, deposition in the lungs was raised to levels similar to or greater than those obtained from a correctly used metered dose inhaler, even in the presence of a suboptimal inhalation technique. The spacer reduced oropharyngeal deposition to only a small fraction of that obtained with a metered dose inhaler alone, and this may explain the reduction in the candida colony count in the oropharynx after inhalation of the corticosteroid aerosol budesonide, which has been observed with this spacer device." The effect of the Nebuhaler on the incidence of dysphonia after corticosteroid aerosol inhalation is not known. Our findings suggest, however, that less drug would be deposited in the upper airways (larynx and above) with Nebuhaler so that a lower incidence of dysphonia might be expected.

We compared the results of the present study with those of a previous study from our laboratories in

Table 3 Mean (SEM) values of variables of radioaerosol inhalation in nine subjects with obstructive airways disease

\begin{tabular}{|c|c|c|c|c|c|c|c|}
\hline & \multicolumn{4}{|c|}{ First inhalation } & \multicolumn{3}{|c|}{ Second inhalation } \\
\hline & $\begin{array}{l}\text { Delay after } \\
\text { firing dose } \\
(s)\end{array}$ & $\begin{array}{l}\text { Inhaled } \\
\text { volume } \\
\text { (l) }\end{array}$ & $\begin{array}{l}\text { Average } \\
\text { inhaled } \\
\text { flow rate } \\
\text { (l/min) }\end{array}$ & $\begin{array}{l}\text { Breath holding } \\
\text { pause } \\
(s)\end{array}$ & $\begin{array}{l}\text { Inhaled } \\
\text { volume } \\
\text { (l) }\end{array}$ & $\begin{array}{l}\text { Average } \\
\text { inhaled } \\
\text { flow rate } \\
(\text { l/min })\end{array}$ & $\begin{array}{l}\text { Breath holding } \\
\text { pause } \\
\text { (s) }\end{array}$ \\
\hline $\begin{array}{l}\text { Metered dose inhaler alone } \\
\text { Nebuhaler (single puffs) } \\
\text { Nebuhaler (multiple puffs) }\end{array}$ & $\begin{array}{l}1 \cdot 2(0 \cdot 2) \\
1 \cdot 3(0 \cdot 1) \\
1 \cdot 4(0 \cdot 1)\end{array}$ & $\begin{array}{l}2.11(0.28) \\
2.01(0.23) \\
2.52(0.34)\end{array}$ & $\begin{array}{l}25 \cdot 0(6 \cdot 0) \\
30 \cdot 2(6 \cdot 3) \\
28.6(7 \cdot 2)\end{array}$ & $\begin{array}{l}12.0(0.4) \\
11.3(0.4) \\
12.3(0.4)\end{array}$ & $\begin{array}{l}2.02(0.29) \\
2.29(0.35)\end{array}$ & $\begin{array}{l}28.0(6.0) \\
36.8(11.5)\end{array}$ & $\begin{array}{l}11.6(0.5) \\
11.4(0.5)\end{array}$ \\
\hline
\end{tabular}


which a cone spacer of similar dimensions but lacking the one way valve in the mouthpiece was used. Use of this device resulted in about $60 \%$ of the dose being deposited in the oropharynx, $13 \%$ in the lungs, and only $20 \%$ in the spacer itself. ${ }^{8}$ The presence of the one way valve enables the spacer device to be used as a holding chamber to contain the aerosol before inhalation, and, although more particles are lost within the spacer, more of the aerosol leaving the device is able to penetrate to the lungs. A smaller holding chamber, the Aerochamber (length about $10 \mathrm{~cm}$, volume about $100 \mathrm{~cm}^{3}$ ) performs a similar function to the Nebuhaler. ${ }^{20}$ In a recent radiotracer study oropharyngeal deposition was reduced 14-fold with the Aerochamber and drug delivery to the lungs was similar to that obtained from a correctly used metered dose inhaler. ${ }^{12}$ Losses within the Aerochamber itself were, however, very high ( $>80 \%$ of the dose). The spacer device has the advantage of large size, which allows more of the aerosol dose to remain suspended within the device and to be potentially available for inhalation; on the other hand) the Aerochamber is more portable and less cumbersome.

These studies suggest that firing four doses in rapid succession into the Nebuhaler and subsequently inhaling them simultaneously is acceptable in terms of drug delivery to the lungs, although it is less efficient than inhaling single puffs. Many patients may find the inhalation of multiple doses a more convenient way of taking metered dose inhalers, particularly for the inhalation of high doses of bronchodilators. There must, however, be a limit to the number of doses that can be released into the spacer in succession, and also to the delay that is permitted before inhalation. Further studies are required to assess these factors.

Several studies of clinical efficacy with either bronchodilator or corticosteroid aerosols have supported the good drug delivery characteristics of the spacer device found in this study. Cross-over studies comparing the metered dose inhaler against large volume holding chambers have shown large volume holding chambers to be more effective, partly because a proportion of the patients had a poor metered dose inhaler technique and hence did not obtain a full effect from the metered dose inhaler alone. ${ }^{9-1121}$ Use of the spacer device may also achieve a clinical effect comparable to or greater than that obtained from an air driven (jet) nebuliser $^{21-23}$ and is by comparison cheaper, more portable, and easier to clean. Nebuhaler is designed for use with specific brands of metered dose inhalers but may fit actuators from several others. This exercise should be performed cautiously as some brands of metered dose inhaler have different spray characteristics, in particular high propellant vapour pressures, which could result in large impaction losses within the device.

\section{APPENDIX}

We have taken a cinefilm of the spray cloud inside Nebuhaler. The cloud appears to expand as it moves away from the actuator, much as it does in free air, $\vec{\omega}$ and a proportion of the dose impacts on the far wall as figure 3 shows. As the spray moves away from the $\overrightarrow{\vec{x}}$ canister it falls slightly under gravity, and this partly accounts for the deposition on the base of the spacer in figure 3. When the cloud reaches the far wall the fraction that has not impacted appears to "double back" and follow a roughly figure of eight course 0 before coming to rest suspended in air within the spacer. A subsequent inhalation from the spacer removes most of the suspended aerosol, although a seond inhalation is recommended to ensure complete emptying.

\section{References}

1 Davies DS. Pharmacokinetics of inhaled substances. Postgrad Med J 1975;51 (suppl 7):69-75.

2 Newman SP, Pavia D, Morén F, Sheahan NF, Clarke SW. Deposition of pressurised aerosols in the human respiratory tract. Thorax $1981 ; 36: 52-5$.

3 Epstein SW, Manning CPR, Ashley MJ, Corey PN. Survey of the clinical use of pressurised aerosol inhalers. Can Med Assoc J 1979; 120:813-6.

4 Coady TJ, Stewart CJ, Davies HJ. Synchronisation of bronchodilator release. Practitioner 1976;217:273-5.

5 Crompton GK. Problems patients have using pressurised aerosol inhalers. Eur J Respir Dis 1982;63 (suppl 119): 101-4.

6 Morén F. Drug deposition of pressurised inhalation aerosols. I. Influence of actuator tube design. International Journal of Pharmaceutics 1978; 1:205-12.

7 Bloomfield P, Crompton GK, Winsey NJP. A tube spacer to improve inhalation of drugs from pressurised aerosols. Br Med J 1979;ii: 1479.

8 Newman SP, Morén F, Pavia D, Little F, Clarke SW. Deposition of pressurised aerosols inhaled through $\mathrm{O}$ extension devices. Am Rev Respir Dis 1981;124:31720.

9 Ellul-Micallef R, Morén F, Wetterlin K, Hidinger KG. Use of a special inhaler attachment in asthmatic chil- N dren. Thorax 1980;35:620-3.

10 Tobin MJ, Jenouri G, Danta I, Kim C, Watson H, 요 Sackner MA. Response to bronchodilator drug $\mathrm{W}$ administration by a new reservoir aerosol delivery sys- $\sigma$ tem and a review of other auxiliary delivery systems. Am Rev Respir Dis 1982;126:670-5.

11 Toogood JH, Jennings B, Baskerville J, Johansson $\mathbb{\mathscr { C }}$ S-A. Clinical use of spacer systems for corticosteroid : inhalation therapy: a preliminary analysis. Eur J Respir Dis 1982;63 (suppl 122): 100-7.

12 Dolovich MB, Ruffin R, Corr D, Newhouse MT. Clinical evaluation of a simple demand-inhalation MDI aerosol delivery device. Chest 1983;84:36-41. 
13 Newman SP, Pavia D, Garland N, Clarke SW. Effects of various inhalation modes on the deposition of radioactive pressurised aerosols. Eur J Respir Dis 1982;63 (suppl 119):57-65.

14 Philipson K. On the production of monodisperse particles with a spinning disc. Journal of Aerosol Science 1973;4:51-7.

15 Hiller FC, Mazumder MK, Wilson JD, Bone RC. Aerodynamic size distribution of metered dose bronchodilator aerosols, Am Rev Respir Dis 1978;118:311-7.

16 Tothill P, Galt JM. Quantitative profile scanning for the measurement of organ radioactivity. Phys Med Biol 1971; 16:625-34.

17 Camner P, Philipson K. Human alveolar deposition of $4 \mu \mathrm{m}$ Teflon particles. Arch Environ Health 1978;36: 181-5.

18 British Pharmaceutical Codex. Aerosol inhalations.
London: Pharmaceutical Press, 1973.

19 Siegel S. Non-parametric statistics for the behavioural sciences. Tokyo: McGraw-Hill Kogakusha, 1956.

20 Corr D, Dolovich M, McCormack D, Ruffin R, Obminski G, Newhouse M. Design and characteristics of a portable breath-actuated, particle size selective medical aerosol inhaler. Journal of Aerosol Science 1982;13:1-7.

21 Cushley MJ, Lewis RA, Tattersfield AE. Comparison of three techniques of inhalation on the airway response to terbutaline. Thorax 1983;38:908-13.

22 Morgan MDL, Singh BV, Frame MF, Williams SJ. Terbutaline aerosol given through a pear-spacer in acute severe asthma. $\mathrm{Br}$ Med J 1982;285:849-50.

23 O'Reilly JF, Buchanan DR, Sudlow MF. Pressurised aerosol with conical spacer is an effective alternative to nebuliser in chronic stable asthma. $\mathrm{Br}$ Med J 1983;286: 1548 . 